Manual of Gastroenterology. 2nd ed. By G L Eastwood, C Avunduk. (Pp 432; illustrated; £22.95.) Boston: Little, Brown, 1994. ISBN 0316199923.

The arrival of a request to review a book can be a mixed blessing. Nice, that someone has remembered that you are still around, but nasty, that you will have to find the time to read the book, and critically. That the book under review turned out to be a manual was a definite blessing, as such a book is not designed to be read cover to cover, but to be dipped into. We decided to use it for eight weeks and refer to it as clinical problems arose.

This turned out to be a big mistake as this approach led to a well thumbed chapter on irritable bowel syndrome and constipation. Berkshire bowel has yet to be written up as a clinical syndrome, but meant we didn't get a chance to read anything on abetalipoproteinaemia. So it was back to the cover to cover approach.

The one important draw back is that the manual is written by Americans and for Americans and thus the abbreviations can get tedious at times. There are also some variations in treatment, such as using mineral oil for the treatment of constipation and using Golytely to treat hepatic encephalopathy. If you grit your teeth this is a draw back worth overcoming as this is an excellent manual at an excellent price.

The format works well, being spiral bound with reasonably lightweight paper but should stand up to being tossed into a briefcase, but won't stand up to being used to prop up the bed head if you get gastro-oesophageal reflux. We advise a multivolume text book of gastroenterology for the latter.

It is absolutely crammed full of information, which is easy to assimilate, concise but not too brief, and amazingly full of common sense. In the section on peptic ulcer and diet the authors comment that 'some patients fee their treatment is inadequate unless a strict diet is prescribed. These patients require a skilful synthesis of the art and science of medicine'. Obviously a manual written by doctors who understand their patients and also listen to them. There is also a section on the changing expectations of doctors and patients over the past 50 years, with respect to consultations, diagnosis, and treatment. This makes interesting and thought provoking reading, in view of the increasing number of complaints that are received by all doctors at present. We think that the next edition should include a chapter on how to deal with complaints!

We whole heartedly recommend this manual to those in training in gastroenterology, at all levels, and it will also be an asset to any ward based library. It is written in a refreshingly unstuffy style and is amazingly cheap. May the next book that comes our way be as useful.

EMMA RAYBOULD MARGARET MYSZOR

Indigestion. By H D Janowitz. (Pp 227; illustrated; £14.95.) New York: Oxford Paperbacks, 1992. ISBN 0195085 54X.

Patient information publications are central to the treatment of chronic conditions. This has long been recognised in the field of diabetes and is now increasingly acknowledged in gastroenterology. During the past decade there has been a proliferation of such booklets, particularly about inflammatory bowel disease. In more recent times leaflets have also appeared on upper gastrointestinal disorders. The success of booklets published by the British Digestive Foundation has confirmed the need for this type of publication.

Initial anxieties about the effect of such information on patient anxiety levels and increased consultation rates have not been confirmed. Indeed, it seems probable that better educated patients make more informed use of medical resources. Indeed, the whole direction of clinical care is now towards better informed patients. The concept that 'doctor knows best' is no longer valid. Indeed, perhaps the patient knows best.

Against this background you would expect that a booklet such as Indigestion to be of particular value in the treatment of patients with dyspepsia and gall stones. This booklet was specifically prepared for an American readership and has been described by Dr Lester Coleman as a 'brilliant and concise treasure trove of information'. I would have to say that it is an excellent summary of our current understanding of both gastroduodenal, biliary, and pancreatic disorders. For medical students it provides a quick and easily read review. I seriously doubt, however, whether a large number of British patients would find the text one they could understand, or indeed one they could afford. The text is well written and fluent. It is clearly on a par with the type of information found in quality newspapers. Unfortunately most of my patients read tabloids rather than broadsheets so it is quite clear that effective patient information must be written in precise but simple and shor sentences. Readability of patient information is critical to its success and it does not correlate with well constructed long sentences. I cannot believe that the average patient will gain greatly from reading this text

J F MAYBERRY

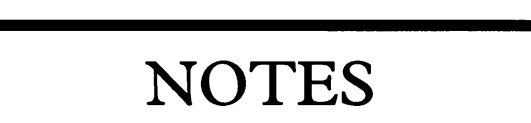

\section{Gut infections}

The Royal College of Pathologists is holding a symposium on An Update on Gut Infections in London on 5 July 1995. Further details from: Scientific Meetings Officer, RCPath, 2 Carlton House Terrace, London SW1Y 5AF. Tel: 01719305862 ext: $24 / 25$.

\section{Clinical nutrition}

The Leeds Course in Clinical Nutrition will be held on 5-8 September 1995. Further particulars from: Mrs Hilary L Thackray, Department of Continuing Professional Education, Continuing Education Building, Springfield Mount, Leeds LS2 9NG. Tel: 01133223233.

\section{Gastroenterology and endoscopy}

The 3rd Munich Postgraduate Course on Gastroenterology and Endoscopy will be held on 13-15 September 1995 in Munich, Germany. Further information from: $T$ Rösch MD/Bridget Fischer, Department of Internal Medicine II, Technical University of
Munich, Klinikum rechts der Isar, Ismaninger Str 22, 81675 München, Germany. Tel: 0894140 2263; fax: 0894140 4872 .

\section{Digestive diseases}

The XXIV Panamerican Congress of Digestive Diseases and Digestive Endoscopy will be held in Belo Horizonte/MG/Brazil on 13-17 November 1995. Information from: Congress LTDA, XXIV Panamerican Congress of Digestive Diseases and Digestive Endoscopy, Av Francisco Sales, 555/1 ${ }^{\circ}$ andar, 30.150-220 Belo Horizonte/MG/ Brazil. Tel: 5531273 1121; fax: 5531273 4770 .

\section{Laparoscopic surgery}

A European Course on Laparoscopic Surgery will be held on 21-24 November 1995. Further information from: Conference Services sa, Avenue de l'Observatoire, 3 bte 17, B-1 180 Bruxelles, Belgium. Tel: 322375 16 48; fax: 3223753299 .

\section{Pancreatic carcinoma}

The European Postgraduate Gastro-Surgical School is organising an international congress on management of pancreatic carcinoma in Amsterdam on 30 November to 1 December 1995. Further information from: Helma Stockmann, Managing Director European Postgraduate Gastro-Surgical School, Room G4-109.3, Academic Medical Center, Meibergdreef 9, $1105 \mathrm{AZ}$ Amsterdam, the Netherlands. Tel: 3120 5663926; fax: 3120 6914858.

\section{Endoscopy}

The Chinese University of Hong Kong and the Hong Kong Society of Digestive Endoscopy will hold the Tenth International Workshop on Therapeutic Endoscopy on 5-7 December 1995. Further information from: Professor Sydney Chung, Endoscopy Centre, The Chinese University of Hong Kong, Prince of Wales Hospital, Shatin, NT, Hong Kong. Tel: 8522632 2233; fax: 8522635 0075 .

\section{ABIM announcement regarding board eligibility}

The American Board of Internal Medicine is planning to undertake a complete review of its policies concerning board eligibility. The ABIM anticipates that revised board eligibility policies will be announced by 31 December 1996.

In the interim, the rules concerning the duration and re-establishment of the board eligible status will be suspended. All candidates with this status will continue to be regarded as board eligible and therefore able to sit for the certifying examinations in internal medicine or the subspecialties. However, the board's qualifying examination, developed to re-establish board eligibility, will not be offered.

Candidates who have questions about this policy should contact the American Board of Internal Medicine, 3624 Market Street, Philadelphia, PA 19104-2675, USA. 